\title{
Fisheries yield and primary productivity in large marine ecosystems
}

\author{
Lorenza Conti ${ }^{1}$, Michele Scardi ${ }^{2, *}$ \\ ${ }^{1}$ Department of Ecology and Sustainable Economical Development, Tuscia University, Largo dell'Università, \\ 01100 Viterbo, Italy \\ ${ }^{2}$ Department of Biology, Tor Vergata University, via della Ricerca Scientifica, 00133 Rome, Italy
}

\begin{abstract}
Primary productivity (PP) and fisheries yield were analysed in 14 large marine ecosystems (LMEs), which encompassed temperate boreal shelves and the Eastern Boundary Currents (EBCs), from 1998 to 2002. PP was estimated by means of a depth-integrated neural network model based on Sea-viewing Wide Field-of-view Sensor (SeaWiFS) data and aimed at providing conservative PP estimates. Landings records were extracted from the global spatial database provided by the Sea Around Us Project (SAUP). Correspondence analysis performed on yield data outlined the role played by different trophic levels (TLs) in LME catches. PP temporal variability was significantly and positively correlated to average trophic level of catches $\left(\mathrm{TL}_{\mathrm{c}}\right)$ so that higher yields in less variable ecosystems were characterised by a lower $\mathrm{TL}_{\mathrm{c}}$. From a functional perspective, high PP temporal variability was associated preferentially with demersal fishes and lower yields, while pelagic-dominated catches were harvested in conditions with lower PP variability. Primary production required (PPR) to sustain fisheries in each LME showed that the highest yield occurred in combination with moderate fishing pressure especially when $\mathrm{TL}_{\mathrm{c}}$ was intermediate to low. High fishing pressures were associated with intermediate total yields and high $\mathrm{TL}_{\mathrm{c}}$ a condition which seemed to occur in high-latitude boreal LMEs. The \%PPR and $\mathrm{TL}_{c}$ were used to assess fisheries impact on ecosystems. PP model choice affects the assessment of exploitation levels, in that a more conservative estimation of PP could contribute to a more precautionary approach to fisheries management where high levels of exploitation are more easily attained.
\end{abstract}

KEY WORDS: Primary productivity $\cdot$ Fisheries yield $\cdot$ Large marine ecosystems $\cdot$ PPR $\cdot$ Overexploitation

Resale or republication not permitted without written consent of the publisher

\section{INTRODUCTION}

The relationship between primary productivity (PP) and fisheries yield has been widely demonstrated (e.g. Nixon 1982, 1992, Nixon et al. 1986, Iverson 1990, Nielsen \& Richardson 1996, Sommer et al. 2002, Steingrund \& Gaard 2005). Nixon $(1982,1992)$ and Nixon et al. (1986) showed an empirical relationship between annual yields of fish and autotrophic productivity in a selection of sites, both marine and estuarine, on the basis of the 'agricultural model' (i.e. linking marine PP to nutrient input) and of the trophodynamic approach (Lindeman 1942). Longer time series and enhanced measurement technologies, together with an improved knowledge of marine food web dynamics, demonstrated that this relationship is not a simple one and often not even linear. Iverson (1990) related nekton production (fish and squids) from offshore areas to the amount of nitrogen incorporated into phytoplankton biomass, the 'new production' being the only type of PP that directly affects fish yields (Nielsen \& Richardson 1996). Variations in food web structure have also been linked to different nutrient richness scenarios in oligotrophic, upwelling and temperate seas (Sommer et al. 2002). Two main models have been proposed to describe marine ecosystems dynamics: (1) bottom-up control, where food web components are regulated by either primary producers or the input of limited nutrients (White 1978), and (2) top-down control, where lower food web components are regulated by one or several upper-level predators (Hairston et al. 1960, Fretwell 1977, 1987, Oksanen et al. 1981, Power 1992, 
Pace et al. 1999, Cury et al. 2001). Several studies pointed out that both systems act locally (e.g. Ware \& Thomson 2005, Mueter et al. 2006, Mackinson et al. 2008).

The shift from local to regional and global spatial scales, added to the potential effects of climate change and regime shifts, highlights the complexity that underlies marine food webs. Cyclic and punctual events, both environmental and anthropogenic, influence the structure and functioning of marine ecosystems, hindering the identification of the relative role of each driving force. Landings statistics are the main source of data for these kinds of studies, representing the only spatial and temporal large-scale data sets available for the detection of different sources of variation. Recently, Perry \& Schweigert (2008) suggested that these highly aggregated data and large (often global) spatial domains may have played a key role in the identification of the general relationship between PP and fisheries yields. The primary criticism about large-scale fisheries studies is their reliance on poor quality of data: landings might not correspond to real abundance due to changing market demand or selectivity of fishing gears, together with uncertainties about catch reporting systems. Nevertheless, it is generally considered that there is a certain degree of association between relative abundance in the landings and in the ecosystem from which these landings are extracted (Halley \& Stergiou 2005). Furthermore, landings represent the best and only available source for regional and global studies.

Substantial advances have been made in PP estimation procedures, reducing at least one of the sources of variation in studies aimed at relating PP and fisheries yield. For a long time, ship-based estimates and chronic undersampling made it difficult to resolve lowfrequency spatial and temporal variability, and forced an estimation of global PP based on the extrapolation of sparse (in time and space) measurements (Carr et al. 2006). Satellite observation of ocean colour, since the beginning of the Sea-viewing Wide Field-of-view Sensor (SeaWiFS) mission in September 1997, determined the shift from a local snapshot view to synoptic and large-scale images, thereby allowing considerable advances in estimation accuracy on a global perspective. The range of modelling approaches for estimating primary productivity from satellite chlorophyll a (chl a) measurements and modelling performances are summarised in Carr et al. (2006). According to Field et al. (1998), global PP is evenly supported by terrestrial and marine photosynthesis, the latter being conveyed for the most part (up to $90 \%$ ) towards production at higher trophic levels (TLs), sustaining three-quarters of global fisheries yields (Myers \& Worm 2003). The total amount of carbon fixed by autotrophs, mainly phyto- plankton, sets the ultimate threshold to the production at higher TLs (Friedrichs et al. 2009) and the possibility of reaching this maximum sustainable production is determined by the structure and functioning of the underlying food web by means of transfer efficiencies (TEs). Typically, $13 \%$ of phytoplankton PP is transferred to herbivore mesozooplankton and benthos, while the 'zooplankton/zoobenthos $\rightarrow$ fish' step is characterised by a TE of $10 \%$ (Ware 2000). From a more general perspective, ecological efficiency in marine ecosystems ranges from 5 to $20 \%$ (Lindeman 1942) depending on the food web structure (i.e. number of trophic levels involved) and decreases with higher trophic levels due to increased respiration (Christensen \& Pauly 1993, Trites 2001).

The relative importance of carbon pathways in different marine ecosystems reflects both the intrinsic properties of primary producers and physical forcing. In oceanic ecosystems, the bulk of phytoplankton production is conveyed through the herbivory chain that sustains production at higher TLs, which in turn is subjected to industrial harvest (Duarte \& Cebrián 1996). Different marine PP estimation algorithms (depth-integrated models and general circulation models [GCMs], coupled with ecosystem or biogeochemical models) converge on a global marine PP annual value of 45 to $50 \mathrm{Gt} \mathrm{C} \mathrm{yr}^{-1}$ (Carr et al. 2006).

The purpose of the present study was to investigate the relationship between primary productivity and fish yield through satellite observations and reported fisheries landings from 14 selected large marine ecosystems (LMEs). We adopted a double approach for relating PP and fish production: (1) bottom-up, where available PP fixes the threshold for production at higher TLs, and (2) top-down, where the primary production required (PPR) to support production at the exploited level was assessed from landing biomass under the assumption that reported landings effectively reflect total fish production (Pauly \& Christensen 1995).

From an ecosystem-based management perspective, PPR provides an estimation of the ecosystem's carrying capacity based on its actual exploitation, and therefore represents a potential guideline for the future. In particular, the relationship between PPR normalised to the $\mathrm{PP}(\% \mathrm{PPR})$ and the averaged TL of catches $\left(\mathrm{TL}_{\mathrm{c}}\right)$ have been proposed as indicators of ecosystems exploitation level (Tudela 2003, Tudela et al. 2005), as $\mathrm{TL}_{\mathrm{c}}$ actually reflects the strategy of a fishery in terms of the food web components selected (Pauly et al. 1998, Christensen \& Walters 2004).

The purpose of this approach is to provide new insights into ecosystem functioning and to give a contribution to key issues in management strategies. It is within the boundaries of the 66 LMEs that major efforts are presently under way to meet the World Summit on 


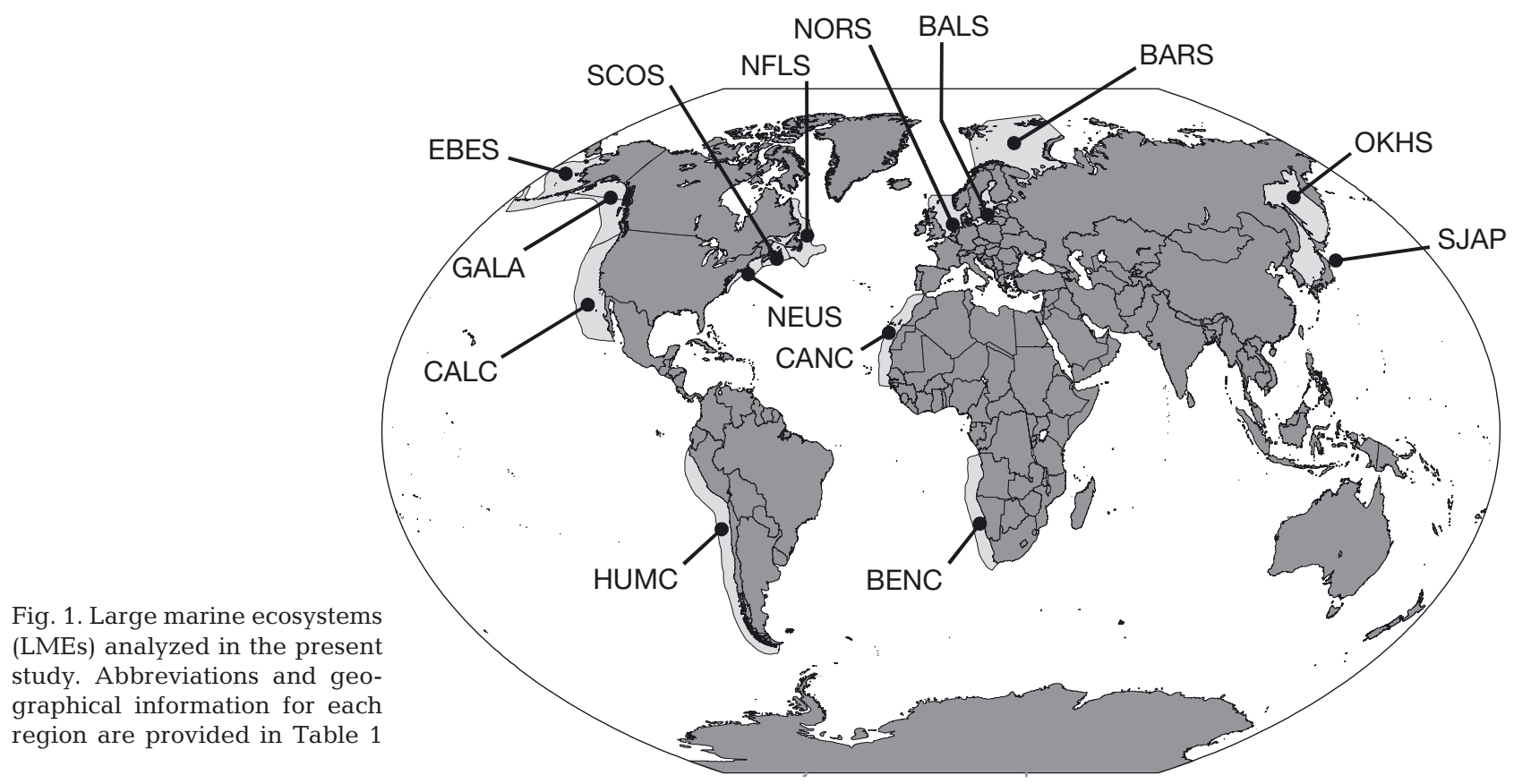

Sustainable Development (WSSD) deadlines, namely: (1) introducing an ecosystem approach to marine resource assessment and management by 2010, and (2) maintaining fish stock maximum sustainable yield levels by 2015. While these standards are still far from being reached, there is a general agreement on the reference space-based ecosystem unit of LMEs, for which a 5-modules strategy of assessment (productivity, fish and fisheries, pollution and ecosystem health, socioeconomics and governance) has been developed (Sherman et al. 2005). In this context, the present paper proposes a focus on the first 2 modules, productivity and fisheries, even though any attempt to better understand ecosystem functioning has important outcomes on all LME strategy components.
Table 1. Acronyms and geographical information for each LME mapped in Fig. 1. Surface areas are expressed in $10^{6} \mathrm{~km}^{2}$ and centroid coordinates as decimal degrees

\begin{tabular}{|lrrrr|}
\hline Complete name & Abbrev. & $\begin{array}{c}\text { Surface } \\
\text { area }\end{array}$ & Longitude Latitude \\
\hline Atlantic Ocean & & & & \\
Barents Sea & BALS & 1.874 & $37.87 \mathrm{E}$ & $75.81 \mathrm{~N}$ \\
Baltic Sea & BARS & 0.394 & $19.76 \mathrm{E}$ & $58.97 \mathrm{~N}$ \\
North Sea & NORS & 0.696 & $2.71 \mathrm{E}$ & $57.40 \mathrm{~N}$ \\
Newfoundland-Labrador Shelf & NFLS & 0.681 & $53.01 \mathrm{~W}$ & $49.45 \mathrm{~N}$ \\
Northeastern US Continental Shelf & NEUS & 0.310 & $70.42 \mathrm{~W}$ & $41.01 \mathrm{~N}$ \\
Scotian Shelf & SCOS & 0.415 & $61.71 \mathrm{~W}$ & $46.98 \mathrm{~N}$ \\
Pacific Ocean & & & & \\
East Bering Sea & EBES & 1.187 & $168.71 \mathrm{~W}$ & $57.40 \mathrm{~N}$ \\
Gulf of Alaska & GALA & 1.475 & $139.75 \mathrm{~W}$ & $54.06 \mathrm{~N}$ \\
Okhotsk Sea & OKHS & 1.558 & $148.94 \mathrm{E}$ & $53.77 \mathrm{~N}$ \\
Sea of Japan & SJAP & 0.987 & $135.67 \mathrm{E}$ & $41.26 \mathrm{~N}$ \\
Eastern Boundary Currents & & & & \\
Benguela Current & BENC & 1.463 & $12.50 \mathrm{E}$ & $21.25 \mathrm{~S}$ \\
California Current & CALC & 2.216 & $122.51 \mathrm{~W}$ & $33.25 \mathrm{~N}$ \\
Canary Current & CANC & 1.125 & $15.30 \mathrm{~W}$ & $24.65 \mathrm{~N}$ \\
Humboldt Current & HUMC & 2.559 & $75.30 \mathrm{~W}$ & $31.96 \mathrm{~S}$ \\
\hline
\end{tabular}

\section{MATERIALS AND METHODS}

Area. Catch and PP data were obtained for 14 out of the 66 LMEs defined by Sherman et al. (2005). Selected LMEs belong to boreal temperate shelves and major upwelling systems (i.e. the Eastern Boundary Currents [EBCs]) (Fig. 1, Table 1). LMEs are 'regions of ocean and coastal space that encompass river basins and estuaries and extend out to the seaward boundary of continental shelves and the seaward margins of coastal current systems ..., delineated according to continuities in their physical and biological characteristics, including inter alia: bathymetry, hydrography, productivity and trophically dependent populations' (Sherman \& Duda 1999, p. 18). Their extension ranges from $300000 \mathrm{~km}^{2}$ (Scotian Shelf) to over 2.5 million $\mathrm{km}^{2}$ (Humboldt Current). Selected ecosystems are characterised by marked seasonality and by time series that are much more reliable than those from equatorial systems, which are often characterised by 
highly aggregated reported landings (i.e. miscellaneous fishes or invertebrates). The reason for this scarce reliability of data from equatorial regions is to be found in the particular socio-economic conditions of the developing countries bordering these LMEs, where fisheries landings data have been seldom collected on a routine basis.

Primary productivity. Our study is based on regional PP estimates obtained from a neural network global model (Scardi 2000, 2001) and from the basic version of the most popular PP model (i.e. Vertically Generalized Production Model, VGPM, Behrenfeld \& Falkowski 1997). PP in each LME has been estimated from monthly mean satellite-derived measures of surface chl a concentration from SeaWiFS (Level 3) and related ancillary sea surface temperature (SST) and irradiance data (available at: oceancolor.gsfc.nasa.gov/). PP estimates were extracted from global raster data (latitudinal pixel size $=9.766 \mathrm{~km}$ ) from January 1998 to December 2002. PP was estimated by means of a depth-integrated model, the Vertically Generalized Production Neural Network (VGPNN) (Scardi 2000, 2001). VGPNN is based on an artificial neural network that performs a generalised nonlinear regression of PP based on surface chl a concentration and other predictive variables (latitude, longitude, day length, mixedlayer depth, $\mathrm{SST}_{1} \mathrm{P}^{\mathrm{B}}{ }_{\text {opt }}$, i.e. maximum $\mathrm{C}$ fixation rate within a water column, mg C (mg chl) ${ }^{-1} \mathrm{~h}^{-1}$ [following Behrenfeld \& Falkowski 1997] and photosynthetically active radiation [PAR]). Neural networks have been recently introduced in ecological modelling and their applications are becoming more and more frequent. They do not require an explicit formulation, as they are able to adapt themselves for reproducing complex relationships, provided that enough data are available and that they account for the effects of the most important sources of variation to be modelled. Further details about the specific modelling strategies adopted for developing the VGPNN model can be found in Scardi (2000, 2001), whereas a more general introduction to the modelling applications of artificial neural networks in coastal marine ecosystems can be found in Scardi (2003).

A special feature of the VGPNN is that it was calibrated (commonly referred to as 'trained') on the basis of a data set in which records with high productivity to biomass (P/B) ratio (depth-integrated primary productivity to biomass in the surface layer ratio) were filtered out. In fact, major distortions in vertically integrated PP may arise when deep chlorophyll (and therefore PP) maxima are associated with low chlorophyll concentrations in the upper layer of the water column. In most cases PP estimates are vertically integrated taking into account samples collected at a few discrete depths. The depth difference between sam- ples is usually not constant, as it increases with depth, and therefore samples are more sparse in the deeper part of the water column. Thus, a deep PP maximum, which is usually confined to a layer much thinner than the depth difference between 2 sampling depths, may be artificially spread on the entire stretch between 2 samples because of the trapezoidal vertical integration. Although this source of bias probably accounts for many cases of high PP values associated with relatively low surface phytoplankton biomass, it has often been overlooked in the development of other models. The exclusion of potentially biased records from the data set that supported the VGPNN development made this model conservative in estimating high PP values.

The effects of this feature can be observed by comparing VGPNN PP estimates with those provided by other depth-integrated models. For instance, the estimate for annual global PP obtained from the VGPM (Behrenfeld \& Falkowski 1997) is $43.5 \mathrm{Gt} \mathrm{C} \mathrm{yr}^{-1}$, while VGPNN provided a lower estimate of $40 \mathrm{Gt} \mathrm{C} \mathrm{yr}^{-1}$ (Carr et al. 2006).

Average values for each LME were computed from monthly global PP raster data. Some missing values at high latitudes, due to reduced day length and cloud cover, were computed by linear interpolation for the Baltic Sea (November to January 1997 and December to January 1999 to 2002), Barents Sea (November to February 1998 to 2002), East Bering Sea (December) and the North Sea (December).

Catches. Yield data were obtained from the Sea Around Us Project (SAUP 2006) catch database, which provides a $50 \mathrm{yr}$ time series of fisheries landings (1950 to 2004) from 66 LMEs around the world, accounting for $83 \%$ of the global fisheries yield (Worm et al. 2006). Yield data are available as average annual catches (metric tons) of each taxon (species, genus or family) within each LME. To compare data from different LMEs, catches are expressed as average values per unit surface area ( $\mathrm{t} \mathrm{km}^{-2} \mathrm{yr}^{-1}$ ).

Yield data were also aggregated by TL, following SAUP database TLs attribution. Five TL classes were defined, namely L225 (TL, 2.25 to 2.75), L275 (TL, 2.75 to 3.25 ), L325 (TL, 3.25 to 3.75 ), L375 (TL, 3.75 to 4.25 ) and L425 (TL, 4.25 to 4.75 ). Species with TL of $<2.25$ were excluded from the analysis as there are no nektonic species below this threshold - with the exception of Mugil cephalus (TL $=2.13$ ) and Sarpa salpa (TL = 2.01), whose contribution to the overall fish yield is negligible. When reported, $M$. cephalus was considered as part of L225; Mugilidae (TL $=2.3$ ) were also reported in this group. $S$. salpa was excluded from the analysis as total catches in the Benguela Current (1998 to 2002) were below $2 \mathrm{t}$. All benthic invertebrates were excluded independently of their TLs. 
Multivariate analysis. A correspondence analysis (CA) (Benzecri 1973) was performed on averaged catches per TL class for each LME $\left(\mathrm{t} \mathrm{km}^{-2} \mathrm{yr}^{-1}\right)$. PP temporal variability (as the variation coefficient of the average monthly LME PP) and total yield were represented as bubble plots in CA ordinations. PP spatial variability (as the average monthly LME PP variation coefficient) was also taken into account.

Primary production required to sustain catches. Following Pauly \& Christensen (1995), PPR to sustain LME catches was computed as:

$$
\mathrm{PPR}=(\text { catches } / 9) \times 10^{(\mathrm{TL}-1)}
$$

Although landings represent only a fraction of the total biomass available in the ecosystem, PPR still represents an indicator of energy TE of the food web. A $\mathrm{PPR} / \mathrm{PP}$ ratio (\%PPR) was assumed as an energetically based fishing pressure index (FPI) to assess yields in relation to intrinsic energetic limits for each LME (Knight \& Jiang 2009). The \%PPR in combination with $\mathrm{TL}_{\mathrm{c}}$ was also used to visually assess LME exploitation level (Tudela 2003, Tudela et al. 2005).

Moreover, following Shannon et al. (2009), 2 ecosystem indicators were computed from reported catches to highlight fisheries impacts in exploited ecosystems: (1) the fish/invertebrates ratio (F/I) and (2) the demersal fish and chondrichthyan fish/pelagic fish ratio $(\mathrm{D} / \mathrm{P})$. For each indicator, the median value over the 5 yr (1998 to 2002) was assumed as a measure for the 'ecosystem state' (Shannon et al. 2009). The analysis of these and other indices over a time lapse was proposed by Shannon et al. 2009 as a tool to detect overexploitation effects, as a decrease of $\mathrm{TL}_{\mathrm{c}}$, better known as 'fishing down marine food webs' (Pauly et al. 1998). Under high harvesting pressures, a decline of these indicators is likely to be observed as a signal of top predatory fish removal in overexploited ecosystems, which in turn determines the decrease of $\mathrm{TL}_{\mathrm{c}}$. Therefore, $\mathrm{F} / \mathrm{I}$ and $\mathrm{D} / \mathrm{P}$ median values are 'snapshots' of the actual LME state, which summarises catch composition, in terms of fish/invertebrates and pelagic fish/demersal fish dominance in fisheries landings. This status could be related to different productivity regimes and overall total yields.

\section{RESULTS}

\section{PP estimates and catch trends}

$$
\text { Primary productivity }
$$

Average PP values estimated by VGPNN and VGPM models during the period from 1998 to 2002 are reported in Table 2. Values for VGPNN estimates ranged
Table 2. Average annual primary productivity $\left(\mathrm{mg} \mathrm{C} \mathrm{m}^{-2} \mathrm{~d}^{-1}\right)$ in each LME estimated for the period from 1998 to 2002 with the Vertically Generalized Production Neural Network (VGPNN; Scardi 2000, 2001) and Vertically Generalized Production Model (VGPMi Behrenfeld \& Falkowski 1997) models

\begin{tabular}{|lcc|}
\hline LME & VGPNN & VGPM \\
\hline Atlantic Ocean & & \\
Baltic Sea & 1527 & 1914 \\
Barents Sea & 642 & 965 \\
North Sea & 820 & 1471 \\
Newfoundland-Labrador Shelf & 363 & 521 \\
Northeast US Continental Shelf & 835 & 1228 \\
Scotian Shelf & 549 & 757 \\
Pacific Ocean & & \\
East Bering Sea & 446 & 652 \\
Gulf of Alaska & 453 & 709 \\
Okhotsk Sea & 465 & 671 \\
Sea of Japan & 416 & 628 \\
Eastern Boundary Currents & & \\
Benguela Current & 988 & 1294 \\
California Current & 367 & 628 \\
Canary Current & 774 & 1494 \\
Humboldt Current & 629 & 874 \\
\hline
\end{tabular}

from $363 \mathrm{mg} \mathrm{C} \mathrm{m}^{-2} \mathrm{~d}^{-1}$ in the Newfoundland-Labrador Shelf up to $1527 \mathrm{mg} \mathrm{C} \mathrm{m}^{-2} \mathrm{~d}^{-1}$ in the Baltic Sea. A positive trend $(r=0.9636, p<0.01)$ was observed for North Sea PP estimates, which increased gradually from 786 in 1998 to $851 \mathrm{mg} \mathrm{C} \mathrm{m}^{-2} \mathrm{~d}^{-1}$ in 2002.

The Canary Current showed the highest average PP spatial variability, while the Baltic Sea was associated with the lowest extreme. On the other hand, temporal variability was the lowest in the Benguela Current, while the highest variability was observed in the Okhotsk Sea. PP temporal variability and spatial variability display opposite patterns, indicating an inverse relationship between these 2 sources of variation, which is even more evident when LME ranks are taken into account (Spearman rank correlation, $\mathrm{r}_{\mathrm{s}}=-0.6923$, $\mathrm{p}<0.01$ ) (Fig. 2). In fact, spatial heterogeneity is usually lower in ecosystems that are strongly driven by seasonal dynamics, whereas the latter can be completely masked by complex spatial patterns, e.g. ecosystems where physical drivers play a major role. Obviously, spatial and temporal components of PP variability can combine with each other, but only to a limited extent, and therefore an inverse relationship between them emerges as empirical evidence.

Fisheries yields

Average annual fisheries yields for each of the 14 LMEs in the period 1998 to 2002 are reported in Table 3 ('Catches' column). Catch values ranged from $0.32 \mathrm{t}$ 


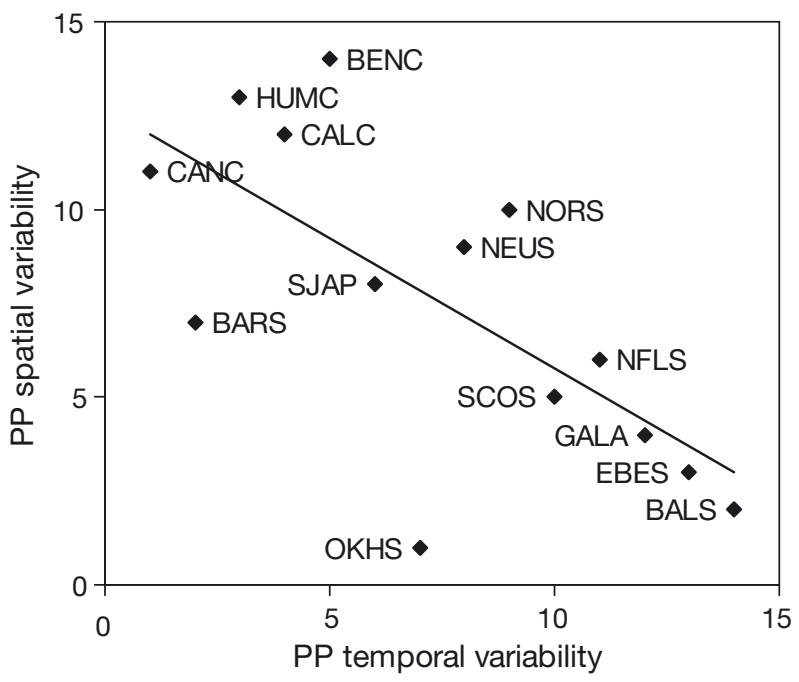

Fig. 2. Temporal versus spatial variability in primary productivity (PP): the rank correlation between the 2 variables is negative and highly significant (Spearman's $r=-0.6923, \mathrm{p}<0.01$ ). See Table 1 for abbreviations

$\mathrm{km}^{-2} \mathrm{yr}^{-1}$ for the California Current LME to $3.93 \mathrm{t} \mathrm{km}^{-2}$ $\mathrm{yr}^{-1}$ in the Humboldt Current. Total yields exhibited significant trends in 3 LMEs: (1) negative trends were observed for the Okhotsk Sea $(r=-0.9830, \mathrm{p}<0.01)$ and the Baltic Sea ( $r=-0.9471, \mathrm{p}<0.05)$; (2) a positive trend was observed for the Benguela Current ( $\mathrm{r}=$ 0.8813, p < 0.05). Significant trends observed for the Baltic Sea and the Benguela Current were related to a decrease or increase in single TL classes. In particular, the negative trend observed in the Baltic Sea was associated with a decrease in L275 catches, which were mainly represented by small pelagic fishes (sprat Sprattus sprattus), while the positive trend in the Benguela Current was associated with an increase in
L375 catches, although this class was the less abundant of the two (up to $5 \%$ in 2002).

In 4 LMEs total catches were dominated by low TL species (L225): in the California Current (41\%), the Newfoundland-Labrador Shelf (46\%), the northeastern US Continental Shelf (51\%) and the Humboldt Current $(85 \%)$, the latter being the most productive marine fishing ground in the world, where catches are indeed totally represented by Peruvian anchoveta Engraulis ringens. The North Sea (59\%), the Canary Current $(53 \%)$ and the Baltic Sea $(45 \%)$ showed prevalent catches in L275, represented by small pelagic species in the Canary Current and the Baltic Sea (sardine or pilchard Sardina pilchardus and sprat, respectively) and by sand eels Ammodytes spp. in the North Sea; these are target species of the largest single-taxon fishery in this region. Intermediate TLs, represented by L325, encompassed top-reported species and accounted for almost one-third of the average total catches through selected LMEs. In addition, 6 of the 14 LMEs showed dominant catches in L325 and L375. Finally, none of the 14 LMEs showed average catches dominated by L425, although the Gulf of Alaska exhibited a particularly high proportion of this TL class (around 28\%), associated with Pacific cod Gadus macrocephalus catches.

\section{Relating PP to fisheries yields}

\section{Total fisheries yield and primary productivity}

Fisheries yields versus PP, following Nixon (1992) and Nixon et al. (1986), are shown in Fig. 3. LMEs and Nixon's ecosystems (Fig. 3) are plotted, together with TE known levels. For each LME, range bars show min-

Table 3. Average fisheries annual catches $\left(\mathrm{t} \mathrm{km}^{-2} \mathrm{yr}^{-1}\right)$, average trophic level of catches $\left(\mathrm{TL}_{\mathrm{c}}\right)$, primary productivity $\left(\mathrm{PP}, \mathrm{g} \mathrm{C} \mathrm{m}^{-2}\right.$ $\left.\mathrm{yr}^{-1}\right)$, primary production required to sustain catches (PPR, $\mathrm{g} \mathrm{C} \mathrm{m}^{-2} \mathrm{yr}^{-1}$ ) and PPR/PP ratio (\%PPR) for each LME. LMEs are ordered by descending \%PPR

\begin{tabular}{|c|c|c|c|c|c|}
\hline LME & Catches & $\mathrm{TL}_{\mathrm{c}}$ & PP & PPR & $\% \mathrm{PPR}$ \\
\hline East Bering Sea & 1.79 & 3.59 & 163 & 116 & 0.71 \\
\hline Sea of Japan & 1.14 & 3.40 & 152 & 100 & 0.66 \\
\hline Okhotsk Sea & 1.61 & 3.52 & 170 & 99 & 0.58 \\
\hline Barents Sea & 2.43 & 3.47 & 234 & 130 & 0.55 \\
\hline North Sea & 3.69 & 3.26 & 299 & 128 & 0.43 \\
\hline Newfoundland-Labrador Shelf & 0.78 & 3.21 & 132 & 48 & 0.36 \\
\hline Gulf of Alaska & 0.35 & 3.82 & 165 & 52 & 0.32 \\
\hline Humboldt Current & 3.93 & 2.72 & 230 & 71 & 0.31 \\
\hline Canary Current & 2.06 & 3.23 & 282 & 76 & 0.27 \\
\hline Benguela Current & 0.94 & 3.48 & 361 & 89 & 0.25 \\
\hline Northeast US Continental Shelf & 1.50 & 3.00 & 305 & 66 & 0.22 \\
\hline Scotian Shelf & 0.70 & 3.31 & 200 & 42 & 0.21 \\
\hline California Current & 0.32 & 3.11 & 134 & 19 & 0.14 \\
\hline Baltic Sea & 0.45 & 3.33 & 557 & 15 & 0.05 \\
\hline
\end{tabular}




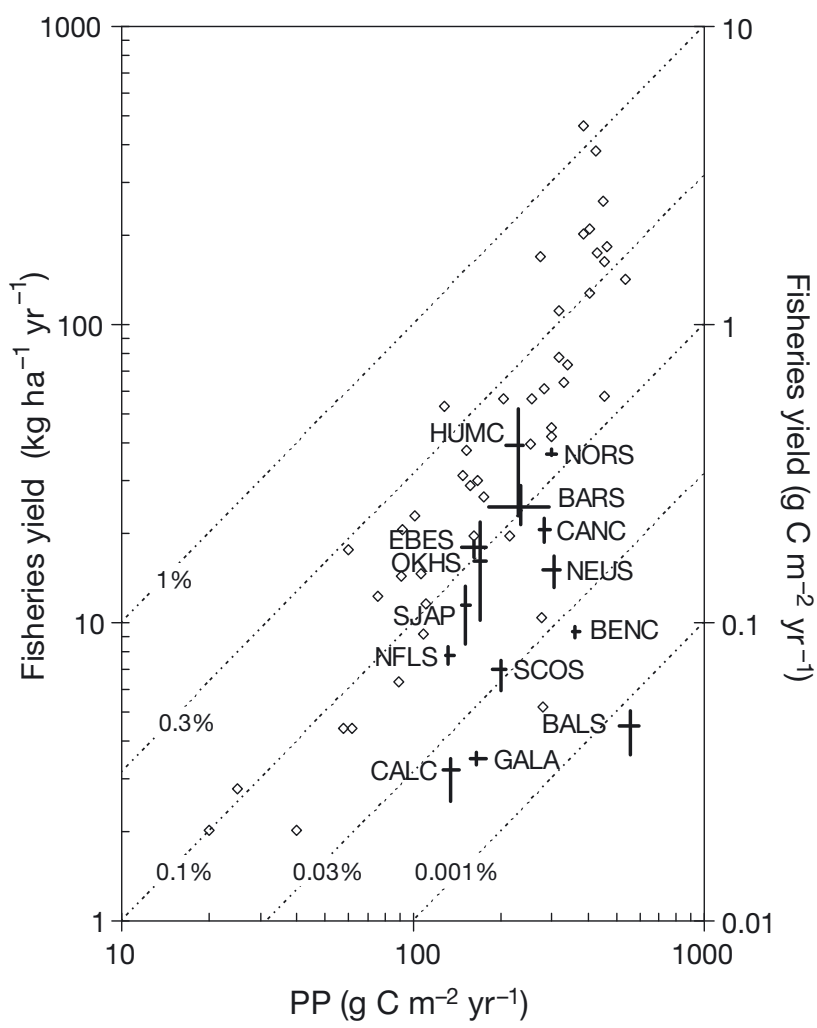

Fig. 3. Relationship between primary productivity (PP) and fisheries yield, following Nixon $(1982,1992)$ and Nixon et al. (1986). Symbols $(\diamond)$ represent Nixon's ecosystems. Variability in PP (horizontal bars) and total yield (vertical bars) are shown for each LME. Diagonal lines and associated \% values show different levels of efficiency in energy transfer from PP to fisheries yield (see 'Results' for details; see Table 1 for abbreviations)

imum and maximum annual PP from 1998 to 2002. While values on the PP axis are comparable amongst LMEs (with the Baltic Sea and the Barents Sea showing the highest range, i.e. 85 and $111 \mathrm{~g} \mathrm{C} \mathrm{m}^{-2} \mathrm{yr}^{-1}$, respectively), a greater and more widespread variability is apparent on the yield axis. In other words, fisheries yields can be quite different despite similar ecosystem PP (e.g. Fig. 3; the Humboldt Current, the Okhotsk Sea and the Sea of Japan show considerable differences in total yields and negligible differences in $\mathrm{PP}$ ). It follows that PP in these systems, although setting the potential for target (and non-target) species, may not represent the main driving force for the harvest, as fisheries yields actually originate from a complex combination of different factors, both biological and industrial (management policies, fishing effort and commercial interests). Thus, PP and fisheries landings could represent input and output variables of a 'black box' into which natural systems dynamics act under the influence of industrial exploitation strategies. Even though these remain known, the efficiency of the com- plex relationship between PP and landings could be represented by overall TE, which provides a rough measure of the effect of harvesting. The efficiency of this complex relationship is represented by overall TE, which provides a rough measure of the effect of harvesting. Total yields in different LMEs are in fact characterised by different average TLs, so that for any given level of PP, TE may vary according to the combination of exploitation pressures on each TL. While overall TEs in Nixon et al. (1986) ranged from 0.1 to $1 \%$, the estimated values obtained in the present study are smaller $(0.01$ to $0.3 \%)$. However, it must be pointed out that high overall TEs in Nixon et al. (1986) were reported mainly for estuaries and near-shore shelves, with an exception made for the Humboldt Current, which still expressed the highest TE in our data set.

\section{Multivariate analysis}

The CA ordination of average catches per TL class for each LME is shown in Fig. 4. Three main features arise from the ordination: (1) the lowest TL class (L225) is isolated from the others and it drives the ordination, (2) the second TL class (L275) is separated from the 3 subsequent TLs and (3) intermediate TLs are close to each other (L325 and L375). The upper TL class (L425) does not appear to contribute in a relevant way to the ordination along the first axis (CA1 in Fig. 4). Moreover, LMEs are associated with different dominant TL classes: in particular, 3 out of 4 EBCs are associated with low TL classes (the Humboldt Current and the California Current with L225 and the Canary Current with L275), while intermediate TLs seem to be associated with temperate shelves and sub-polar ecosystems (e.g. East Bering Sea, Gulf of Alaska, Okhotsk Sea, Scotian Shelf). Demersal-dominated ecosystems (East Bering Sea, Gulf of Alaska, Okhotsk Sea and New-

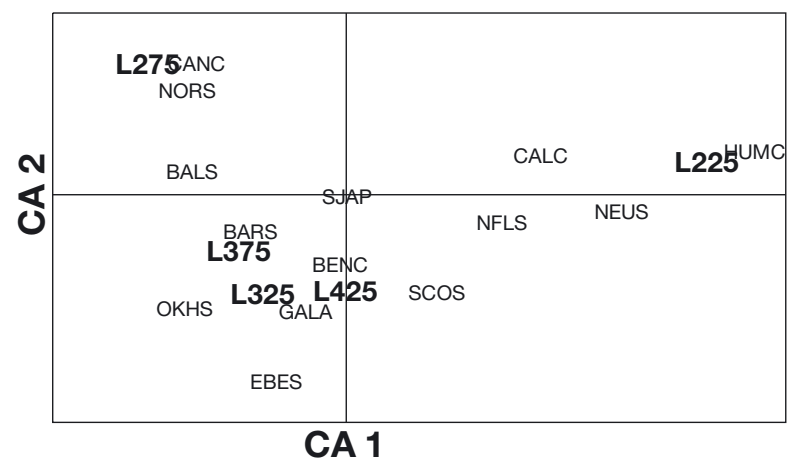

Fig. 4. Correspondence analysis (CA) of LMEs and trophic levels. This ordination shows the role that trophic levels (TLs) play in each LME (see Fig. 1, Table 1 for abbreviations of LME names) 

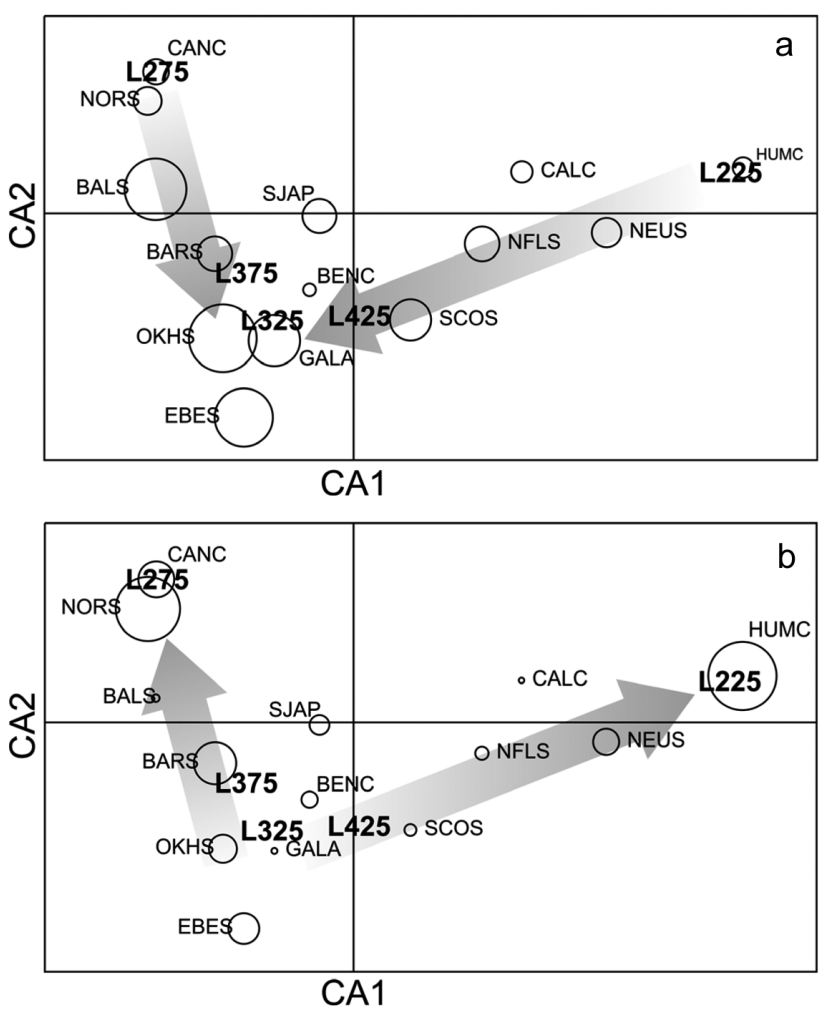

Fig. 5. Correspondence analysis: bubble size represents (a) primary productivity (PP) temporal variability and (b) total fisheries yield. As suggested by the grey arrows, temporal variability is minimum in LMEs where lower TLs, especially L225, play a major role. In contrast, total yield is maximum in these LMEs, as the overall efficiency of energy transfer is negatively correlated to the exploited TL. See Table 1 for abbreviations

foundland Labrador Shelf) were located in the negative CA2 semi-plane (Fig. 4), with the only exception being the North Sea, which is associated with L275 catches (see also Fig. 8).

Information about PP temporal variability and total yields was displayed in the CA ordination plot by turning the plot into 2 bubble plots (Fig. 5a,b). A general relationship between the PP temporal variability and the composition of catches is apparent: a high PP temporal variability, indicating marked seasonal variations (Fig. 5a), seemed to favour upper and intermediate TLs (L325, L375 and L425), whereas low TL catches (L225 and L275) are associated with much more stable ecosystems (Fig. 5a) and higher yields (Fig 5b). In other words, the fisheries yield under conditions of high PP variability is associated with intermediate TLs (demersal catches) and is generally lower than in more stable fishing grounds, where pelagic-dominated (low TLs) harvests produce the world's highest yields in marine fisheries. Average PP and spatial variability are not presented here as they did not show any clear pattern in association with total yields.

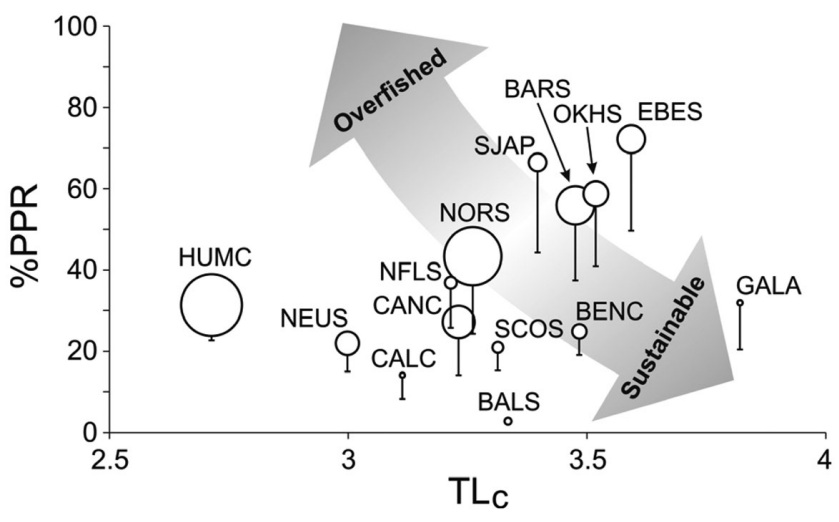

Fig. 6. \%PPR versus $\mathrm{TL}_{\mathrm{c}}$ relationship: \%PPR estimates for each LME based on the VGPNN model (Scardi 2000, 2001) are shown, while the lower end of the vertical bars show \%PPR according to the VGPM model (Behrenfeld \& Falkowski 1997). Vertical bars outline the difference between a $\%$ PPR estimate based on VGPNN (bubble) and an estimate provided by the VGPM model, i.e. the effect of uncertainty due to the PP model selection. Bubble size represents LME's total yield. See Tables $1 \& 2$ for abbreviations

Primary productivity required to sustain total yields

Estimated PP values ranged from 132 to $557 \mathrm{~g} \mathrm{C} \mathrm{m}^{-2}$ $\mathrm{yr}^{-1}$, while PPR values ranged from 15 to $130 \mathrm{~g} \mathrm{C} \mathrm{m}^{-2}$ $\mathrm{yr}^{-1}$ (Table 2). In Fig. 6, \%PPR (PPR/PP) estimates are plotted against the average TL of catches in a bubble plot, where the bubble size represents the total yields. The highest yields occur in combination with moderate fishing pressures $(0.1<\%$ PPR $<0.5$, Fig. 6$)$, especially when the average catch TL is in the intermediate to low range. High fishing pressures (\%PPR > 0.5, Fig. 6) are associated with intermediate total yields and high average TL of catches. This condition seems to occur in high-latitude boreal LMEs $\left(>50^{\circ} \mathrm{N}\right)$ where the stocks are possibly overexploited. A low fishing pressure $(\%$ PPR $<0.1$, Fig. 6$)$ is observed only in the Baltic Sea, where fisheries target relatively low TL species and the PP is very high (up to $600 \mathrm{~g} \mathrm{C} \mathrm{m}^{-2} \mathrm{yr}^{-1}$ in 2002). Obviously, under these conditions an increase in catches can be, in theory, supported by ecosystem production.

For ecosystem indicators computed on fisheries landings (Figs. $7 \& 8$ ), 2 LMEs, both located in the NW Atlantic Ocean, showed an F/I ratio value of $<0$ : the Newfoundland-Labrador Shelf and northeastern US Continental Shelf fisheries harvest invertebrates rather than fish (Fig. 7). The F/I ratio was not computed for the Barents Sea, as invertebrates represent a negligible portion of total catches in this LME. A linear correlation of the F/I ratio in time (1998 to 2002) showed that the northeastern US Continental Shelf exhibited a significant negative trend $(r=-0.98425, p<0.01)$, demonstrating that the dominance of invertebrates in the 


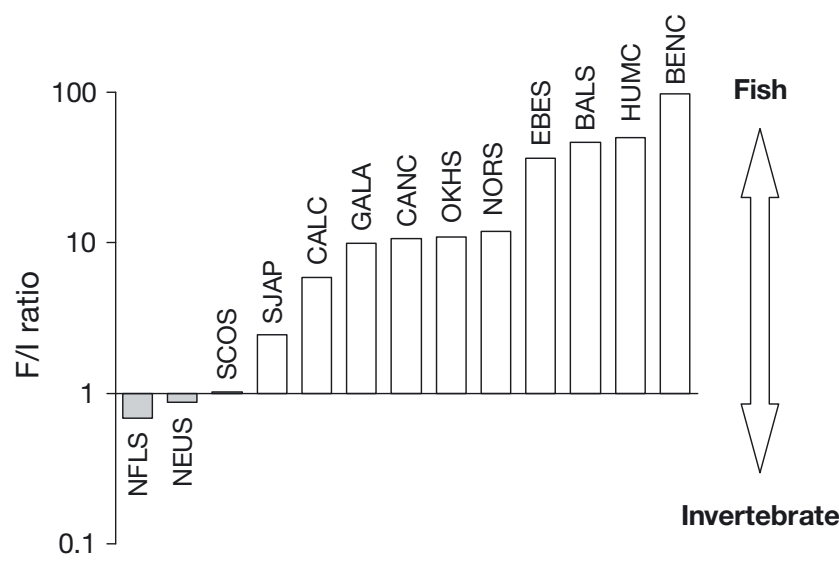

Fig. 7. Average ratio of fish to invertebrates (F/I) following Shannon et al. (2009). Only 2 LMEs, namely NFLS and NEUS, exhibited total fisheries yields dominated by invertebrate species rather than fish species. F/I ratio was not computed for the Barents Sea, as invertebrates represent a negligible portion of the total catches in this LME. See Table 1 for abbreviations

catch became stronger in this period of time. In particular, a shift from fish to invertebrate dominance was observed to occur in 2000. An opposite pattern was observed in the Scotian Shelf, where catches from 1998 to 2000 were invertebrate-dominated, while the last $2 \mathrm{yr}$ of landings were fish-dominated, although a significant linear trend is missing.

The demersal/pelagic composition of fisheries harvests was also assessed through the D/P ratio for LMEs showing a clear dominance in fish catches (Fig. 8). This indicator also provided a rough measure of $\mathrm{TL}_{\mathrm{C}}$, with demersal catches showing an overall higher $\mathrm{TL}_{\mathrm{c}}$ than pelagic ones, especially when pelagic fisheries harvested small and medium-sized species (e.g. anchovies and sardines). The majority of LMEs show pelagicdominated landings: a strong unevenness in catches was observed in the Baltic Sea and Humboldt Current,

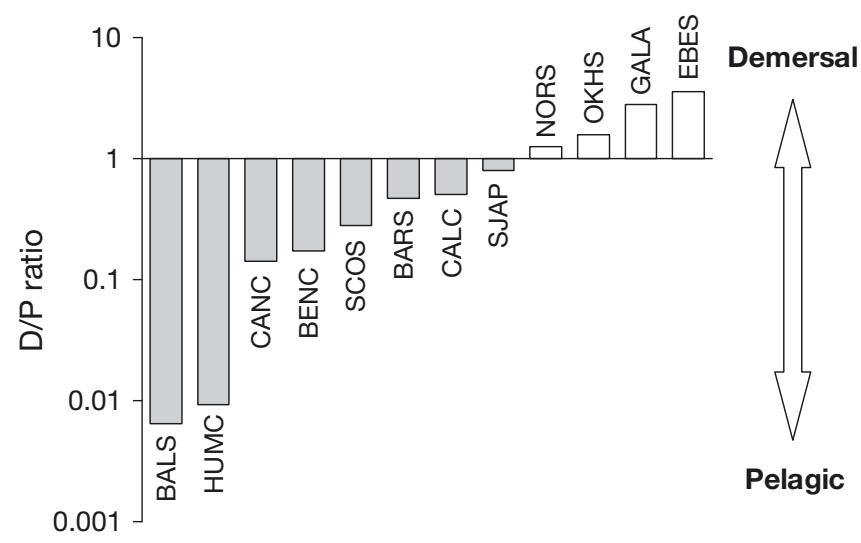

Fig. 8. Average ratio of demersal and chondrichthyans fish to pelagic fish (D/P) following Shannon et al. (2009). See Table 1 for abbreviations where low TL pelagic catches represented almost all landings, but low TLs species were dominant also in the other 3 EBCs (i.e. the Benguela, Canary and California currents) and in the Barents Sea, Scotian Shelf and Sea of Japan. A significant negative trend in D/P ratio over time was observed in the Barents Sea ( $\mathrm{r}=$ $-0.97594, \mathrm{p}<0.01)$ and Scotian Shelf $(\mathrm{r}=-0.97949, \mathrm{p}<$ 0.01), demonstrating an increase in pelagic dominance. Demersal dominance was observed in North Pacific LMEs (Gulf of Alaska, East Bering Sea and Okhotsk Sea) as well as in the North Sea. The latter showed a lower TL, which was associated with a fishing pressure exerted on low to intermediate TLs (L275 in Fig. 4), especially on Ammodytes.

\section{DISCUSSION}

\section{Yield relationship between PP and fisheries}

The present study provides new insights into the PP-fisheries relationship, suggesting that total fisheries yields can be linked more to PP temporal variability than to PP average values, as has been proposed in previous studies (e.g. Nixon 1982, 1992, Nixon et al. 1986, Iverson 1990, Nielsen \& Richardson 1996, Sommer et al. 2002, Steingrund \& Gaard 2005). Moreover, total yields are, in turn, negatively correlated with PP spatial variability as a consequence of the negative correlation between PP spatial and temporal variability. From an ecological perspective it would be reasonable to imagine that fish populations experiencing lower fluctuations in resources availability may profit from regular feeding of larvae and juveniles. This could determine longer reproductive and spawning seasons, which, as a result, may sustain higher yields. At the same time, from a management point of view, it would be only natural to conclude that where seasonal variability is weak, fisheries effort should be organized in a more effective way to obtain higher harvests. Furthermore, the significant relationship between PP temporal variability and $\mathrm{TL}_{\mathrm{c}}(\mathrm{r}=0.5604, \mathrm{p}<0.05)$ points to a strong correlation between environmental variability and catches composition (Fig. 9). Higher yields are typically obtained when low TLs are harvested in ecosystems that experience stable productive regimes. Under these conditions, catches are typically dominated by pelagic species. Obviously, the role of PP variability in determining fisheries yields should be further investigated when longer time series, especially on the fisheries side, are available.

CA shows that intermediate TL classes (L325 and L375) tend to occur simultaneously. This coupling may be governed by intrinsic features of the TL assignment: intermediate TL species may oscillate between slightly 


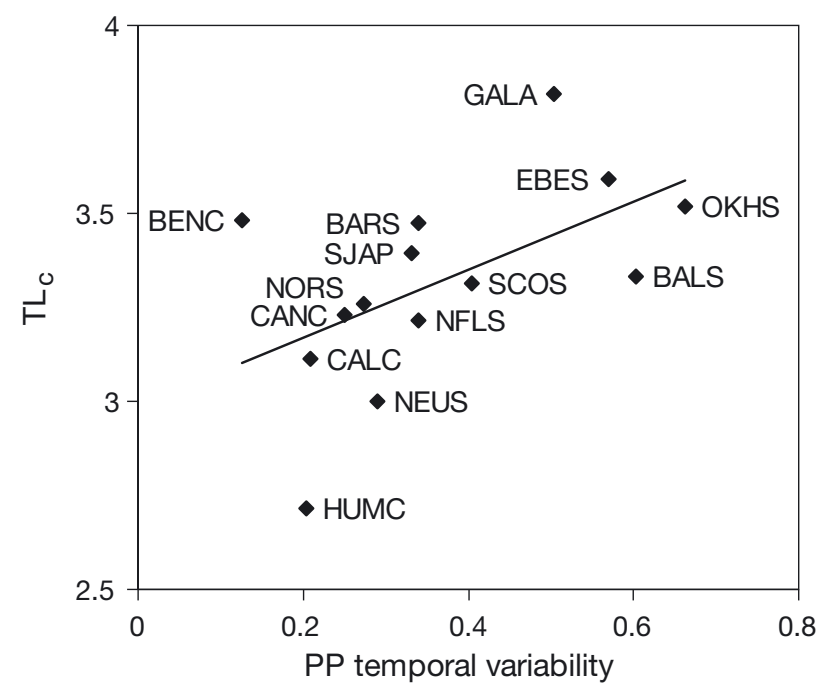

Fig. 9. Average tropihic level of catches $\left(\mathrm{TL}_{\mathrm{c}}\right)$ versus primary productivity (PP) temporal variability: the linear correlation is positive and significant $(\mathrm{r}=0.5604, \mathrm{p}<0.05)$. See Table 1 for abbreviations

different TLs due to variable diets; in contrast, TL definition is more accurate for low TL species (i.e. small pelagic fishes), whose diet is more stable and determined by physiological and morphological characteristics. Nevertheless, co-occurrence of L325 and L375 could also suggest that they share a common feature regarding fishing gear: intermediate TL species are represented mainly by demersal or benthopelagic species, which are usually all targeted by trawls. As indicated previously, intermediate TL species are typical of demersal-dominated catches and are associated with overall lower yields in LMEs characterised by less stable PP conditions.

\section{PPR and ecosystem transfer efficiencies}

Any consideration about PPR is obviously affected by the lack of accuracy in both fisheries and PP data. Uncertainty in these data may lead to widely variable estimates and, in the end, to strikingly different scenarios. PP estimates can be obtained from a number of models, but their range can be as wide as $100 \%$. In the present study, a conservative model (VGPNN, Scardi 2001) was selected, which provides PP estimates close to the lower end of their range. The rationale supporting this choice is that, while other models have been calibrated with PP data that are possibly overestimated because of the artificial spread of PP maxima caused by vertical integration, these records have been filtered out from the VGPNN 'training set' by setting a threshold in the $\mathrm{P} / \mathrm{B}$ ratio. In addition, although we assume that the overestimation of PP can also affect the VGPM model (Behrenfeld \& Falkowski 1997), we compared our results with this model, which is by far the most commonly applied and the most popular template for further developments (Carr et al. 2006). Obviously, the selection of a reference PP model is inherently subjective, as there is no way to prove that any given model is better than others on a global scale (Friedrichs et al. 2009). However, differences between PP models affect the definition of the relative relationships between LMEs only to a limited extent.

An estimated $8 \%$ of the total aquatic PP is required to sustain global fisheries, although shelf and upwelling ecosystems show markedly higher values ranging around 25\% (Pauly \& Christensen 1995). Other PPR values were computed to estimate PP requirements of single-species populations such as the Pacific herring Clupea pallasii in the NE Pacific Ocean and East Bering Sea (Perry \& Schweigert 2008) and North Sea demersal fishes (Jennings et al. 2008). In agreement with previous studies (Pauly \& Christensen 1995, Tudela et al. 2005), we obtained high PPR values for temperate shelves, even though absolute LME-specific PPR values were higher than those reported elsewhere. For example, the East Bering Sea \%PPR was estimated at 0.7 compared with previously reported values of 0.15 to 0.31 (Trites et al. 1997), and the $0.36 \%$ PPR estimated for the Newfoundland-Labrador Shelf is twice the value of 0.15 reported by Heymans (2004) for an overlapping time interval (1995 to 2000).

Upwelling regions show lower PPR values (14 to $30 \%$ ) in association with a fishing effort that targets lower TLs (mainly small pelagic species), so that a lower carbon fraction is necessary to sustain catches in these LMEs. The Baltic Sea was a unique condition among LMEs, where the highest average PP, determined by semi-enclosed conditions, was associated with catches at the lowest end of the TLs, leading to an extremely small PPR value $(<3 \%)$.

In general, the high \%PPRs estimated in the present study are partially attributed to more conservative PP estimates obtained with the VGPNN model, a feature that affects both the assessment of exploitation level and management practices. A relationship between average TL of catch $\left(\mathrm{TL}_{\mathrm{c}}\right)$ and \%PPR has been proposed in Tudela (2003) and Tudela et al. (2005) as an indicator of ecosystem fishing impact. Based on the approach of those authors, 2 sets of \%PPR-TL $\mathrm{TL}_{\mathrm{c}}$ pairs for each LME were plotted (Fig. 6), each obtained with a different PP estimation model (VGPM and VGPNN). The relative location of these 2 blocks in the plot indicates a possible range of variation, which could lead to potentially different management perspectives. Following Knight \& Jiang (2009), choosing the VGPM PP estimation model instead of the VGPNN model could lead to different conclusions in terms of exploitation 
levels. In fact, the threshold of 0.5 FPI indicated by these authors as the limit for an intermediate fishing pressure is not exceeded by LMEs when PP is estimated by VGPM. In contrast, the more conservative estimation of PP obtained with VGPNN determines the shift of high-latitude boreal shelves towards overexploitation (FPI > 0.5). It follows that a more conservative estimation of PP could contribute to a more precautionary approach to fisheries management, where high levels of exploitation are more easily attained. However, although FPI provides a rough measure of fisheries exploitation, it fails to take into account the TL on which fisheries effort is being expressed. The same pressure exerted upon low or high TLs will lead to different exploitation scenarios.

\section{CONCLUSIONS}

The double bottom-up/top-down approach, borrowed from food web theory, allowed us to better focus on which PP aspect acted as the principal driving control for overall fisheries yields (bottom-up) and to assess carbon budget demands (PPR) for individual fisheries in 14 LMEs (top-down). Although it could be considered a crude approach to dealing with such a complex subject, this approach turned out to be effective in addressing general questions on the dynamics underlying exploited ecosystems on a large scale.

After several previous attempts (e.g. Nixon 1982, 1992, Nixon et al. 1986, Iverson 1990, Nielsen \& Richardson 1996, Sommer et al. 2002, Steingrund \& Gaard 2005) that focused on a limited set of records, mainly represented by direct PP measurements and local fisheries statistics, the availability of new remotely sensed data sets allowed an important scaling up to regional or even global studies. These data have been constantly collected since late 1997 in the framework of the SeaWiFS mission, providing a consistent source of information for improved PP estimates. Further advances are associated with recent comparisons between different PP models (Carr et al. 2006, Friedrichs et al. 2009), which contribute substantially in obtaining more accurate global PP estimates and a better and more reliable analysis of the process.

Nevertheless, some limitations intrinsic to these kinds of studies need to be considered. First, the limited spatial scale (e.g. the limited number of LMEs selected) could hinder a global generaliszation, although the LMEs considered encompass the bulk of industrial fishing grounds both in the Northern (e.g. temperate shelves like the North Sea, Baltic Sea and NW Atlantic Ocean) and in the Southern Hemisphere (e.g. major upwelling regions like the Humboldt Current). Second, it must be stressed that further informa- tion is needed to outline more accurate trends and perspectives: for instance, no information about fishing efforts is available at the same resolution as are yield data, so that landings are actually used as an approximation of actual fish catches. Nevertheless, the limited time lapse considered in our work allowed us to reasonably assume a constant exploitation pressure. Obviously, there are potential sources of error in such an assumption (e.g. moratoria measures).

Finally, although we can estimate TEs from an ecological perspective, estimates need to be corrected for external energy budgets. In fact, while the photosynthetic production of organic carbon is supported by solar irradiation, the fisheries harvest is sustained by alternative energy sources (fossil fuels), which guarantee exploitation levels that exceed those supported by natural processes alone. So, even though fishing activities may be considered as a 'top predation', these external energy uploads significantly differentiate fishery from natural predation (Trites et al. 1997).

\section{LITERATURE CITED}

Behrenfeld MJ, Falkowski PG (1997) Photosynthetic rates derived from satellite-based chlorophyll concentration. Limnol Oceanogr 42:1-20

Benzecri JP (1973). L'analyse des données, Vols 1 and 2. Dunod, Paris

Carr ME, Friedrich MAM, Schmeltza M, Aita MN and others (2006) A comparison of global estimates of marine primary production from ocean color. Deep-Sea Res II 53:741-770

Christensen V, Walters CJ (2004) Ecopath with Ecosim: methods, capabilities and limitations. Ecol Model 172:109-139

Christensen V, Pauly D (1993). Flow characteristics of aquatic ecosystems. In: Christensen V, Pauly D (eds) Trophic models of aquatic ecosystems. ICLARM Conf Proc 26. ICLARM, Manila, p 338-352

Cury P, Shannon L, Shin YJ (2001). The functioning of marine ecosystems. In: Reykjavik Conference on Responsible Fisheries in the Marine Ecosystem. Reykjavik, Iceland, 1-4 October 2001. Abstract of the conference

Duarte CM, Cebrián J (1996) The fate of marine autotrophic production. Limnol Oceanogr 41:1758-1766

Field CB, Behrenfeld MJ, Randerson JT, Falkowski P (1998) Primary production of the biosphere: integrating terrestrial and oceanic components. Science 281:237-240

Fretwell SD (1977) The regulation of plant communities by food chains exploiting them. Perspect Biol Med 20: 169-185

Fretwell SD (1987) Food chain dynamics: the central theory of ecology? Oikos 50:291-301

Friedrichs MAM, Carr ME, Barber R, Scardi M and others (2009) Assessing the uncertainties of model estimates of primary productivity in the tropical Pacific Ocean. J Mar Syst 76:113-133

Hairston NG, Smith FE, Slobodkin LB (1960) Community structure, population control, and competition. Am Nat 94:421-424

Halley JM, Stergiou KI (2005) The implications of increasing variability of fish landings. Fish Fish 6:266-276

Heymans S (ed) (2004) Ecosystem models of Newfoundland 
and southeastern Labrador: additional information and analyses for 'Back to the Future'. Fisheries Centre Research Report 11(5). University of British Columbia, Vancouver

Iverson RL (1990) Control of marine fish production. Limnol Oceanogr 35:1593-1604

- Jennings S, van Hal R, Hiddink JG, Maxwell TAD (2008) Fishing effects on energy use by North Sea fishes. J Sea Res 60:74-88

Knight BR, Jiang W (2009) Assessing primary production constraints in New Zealand fisheries. Fish Res 100:15-25

Lindeman R (1942) The trophic-dynamic aspect of ecology. Ecology 23:399-418

Mackinson S, Daskalova G, Heymans JJ, Neira S and others (2008) Which forcing factors fit? Using ecosystem models to investigate the relative influence of fishing and changes in primary productivity on the dynamics of marine ecosystems. Ecol Model 220:2972-2987

Mueter FJ, Ladd C, Palmer MC, Norcross BL (2006) Bottomup and top-down controls of walleye pollock (Theragra chalcogramma) on the Eastern Bering Sea shelf. Prog Oceanogr 68:152-183

> Myers RA, Worm B (2003) Rapid worldwide depletion of predatory fish communities. Nature 423:280-283

> Nielsen E, Richardson K (1996) Can changes in the fisheries yield in the Kattegat (1950-1992) be linked to changes in primary production? ICES J Mar Sci 53:988-994

Nixon SW (1982) Nutrient dynamics, primary production and fisheries yield of lagoons. Oceanol Acta 4(Suppl):357-371

Nixon SW (1992) Quantifying the relationship between nitrogen input and the productivity of marine ecosystems. Proc Adv Mar Tech Conf 5:57-83

Nixon SW, Oviatt CA, Frithsen J, Sullivan B (1986) Nutrients and the productivity of estuarine and coastal marine ecosystems. J Limnol Soc S Afr 12:43-71

Oksanen L, Fretwell SD, Arruda J, Niemela P (1981) Exploitation ecosystems in gradients of primary productivity. Am Nat 118:240-261

Pace ML, Cole JJ, Carpenter SR, Kitchell JF (1999) Trophic cascades revealed in diverse ecosystems. Trends Ecol Evol 14:483-488

Pauly D, Christensen V (1995) Primary production required to sustain global fisheries. Nature 374:255-257

Pauly D, Christensen V, Dalsgaard J, Froese R, Torres F Jr (1998) Fishing down marine food webs. Science 279: 860-863

Perry RI, Schweigert JF (2008) Primary productivity and the carrying capacity for herring in NE Pacific marine ecosystems. Prog Oceanogr 77:241-251

Power ME (1992) Top-down and bottom-up forces in food webs: Do plants have primacy? Ecology 73:733-746

Scardi M (2000) Neural network models of phytoplankton primary production. In: Lek S, Guéguan JF (eds) Artificial neural networks. Application to ecology and evolution. Springer-Verlag, Berlin, p 115-129

Editorial responsibility: Kenneth Sherman, Narragansett, Rhode Island, USA
Scardi M (2001) Advances in neural network modelling of phytoplankton primary production. Ecol Model 146:33-45

Scardi M (2003). Neural network applications in coastal ecological modeling. In: Lakhan VC (ed) Advances in coastal modeling. Elsevier, Amsterdam, p 505-532

SAUP (Sea Around Us) (2006) A global database on marine fisheries and ecosystems. Fisheries Centre, University of British Columbia, Vancouver, www.seaaroundus.org

Shannon LJ, Coll M, Neira S (2009) Exploring the dynamics of ecological indicators using food web models fitted to time series of abundance and catch data. Ecol Indic 9: 1078-1095

Sherman K, Duda AM (1999) Large marine ecosystems: an emerging paradigm for fishery sustainability. Fisheries 24(12):15-26

Sherman K, Sissenwine M, Christensen V, Duda AM and others (2005) A global movement toward an ecosystem approach to management of marine resources. Mar Ecol Prog Ser 300:275-279

Sommer U, Stibor H, Katechakis A, Sommer F, Hansen T (2002) Pelagic food web configurations at different levels of nutrient richness and their implications for the ratio fish production:primary production. Hydrobiologia 484:11-20

Steingrund P, Gaard E (2005) Relationship between phytoplankton production and cod production on the Faroe Shelf. ICES J Mar Sci 62:163-176

Trites AW (2001) Food webs in the ocean: Who eats whom and how much? In: Reykjavik Conference on Responsible Fisheries in the Marine Ecosystem. Reykjavik, Iceland, 1-4 October 2001. Abstract of the conference

Trites AW, Christensen V, Pauly D (1997) Competition between fisheries and marine mammals for prey and primary production in the Pacific Ocean. J Northwest Atl Fish Sci 22:173-187

Tudela S (2003) The pair \% PPR \& $\mathrm{TL}_{\text {fishery }}$ : a possible composite indicator of ecosystem impact aligned with a holistic vision of the Ecosystem-Based Fisheries Management Approach. In: Ecofish Workshop on Sustainability Indicators in Fisheries, 14-16 Apr 2003, Dakar. Abstract of the conference

Tudela S, Coll M, Palomera I (2005) Developing an operational framework for fisheries management on the basis of a two-dimensional index of ecosystem impact. ICES J Mar Sci 62:585-591

Ware DM (2000) Aquatic ecosystems: properties and models. In: Harrison PJ, Parsons TR (eds) Fisheries oceanography: an integrative approach to fisheries ecology and management. Blackwell, London, p 161-194

Ware DM, Thomson RE (2005) Bottom-up ecosystem trophic dynamics determine fish production in the northeast. Pac Sci 308:1280-1284

White TRC (1978) The importance of relative shortage of food in animal ecology. Oecologia 33:71-86

Worm B, Barbier EB, Beaumont N, Duffy JE and others (2006) Impacts of biodiversity loss on ocean ecosystem services. Science 314:787-790

Submitted: August 31, 2009; Accepted: April 19, 2010 Proofs received from author(s): June 22, 2010 